\title{
Physical fitness of children and youth with asthma in comparison to the reference population
}

\author{
Cross-sectional results of the population-based MoMo study in Germany \\ Anke Hanssen-Doose ${ }^{1 *}$, Robert Jaeschke ${ }^{2}$, Claudia Niessner ${ }^{3}$, Doris Oriwol ${ }^{1,3}$ and Annette Worth ${ }^{1}$
}

\begin{abstract}
Background: Physical fitness is an essential marker of health. The literature regarding the question of whether individuals with asthma have reduced physical fitness compared to their non-asthmatic peers is inconsistent and focuses on the cardiorespiratory endurance dimension. This study provides a comparison of different dimensions of physical fitness in individuals with and without asthma on the basis of the German population-based study "KiGGS" (German Health Interview and Examination Survey for Children and Adolescents) and its in-depth study "MoMo" (2009-2012: wave 1 and 2014-2017: wave 2).

Methods: In total, 7731 individuals aged 6-30 years were included in this cross-sectional analysis at two measurement waves, including 353 individuals with and 7378 without asthma. The 12-month prevalence of physician-diagnosed asthma was assessed by interview. Physical fitness was measured by six test items of the MoMo test profile. "Cardiorespiratory endurance" was measured by an ergometric test, "muscular strength" by standing long jump, pushups and sit-ups and "coordination" by jumping sideways and balancing backwards. Because of the broad age range of the sample, age- and sex-specific percentiles were used. Physical activity, age, gender and general state of health were assessed by questionnaire.
\end{abstract}

Results: The individuals with asthma reported a poorer general state of health at both measurement waves. However, the results of the fitness tests indicated that they were as physically fit as their peers without asthma in relation to cardiorespiratory endurance and muscular strength. The mean percentiles were all within the same range. The results of the comparisons of coordination performance were inconsistent. At wave 1 they were within the same range, at wave 2 individuals with asthma showed a poorer coordination performance $(p=0.041 ; \mathrm{HL}=4.125, \mathrm{Cl}$ of $\mathrm{HL}$ 0.155-8.125).

Conclusions: To the best of our knowledge, this is the first study to compare the physical fitness of individuals with and without asthma by considering several dimensions of physical fitness. The study demonstrates that cardiorespiratory endurance and muscular strength are not reduced in individuals with asthma. The results of the comparisons at the two measurement waves were remarkably stable.

*Correspondence: anke.hanssen-doose@ph-karlsruhe.de

${ }^{1}$ University of Education Karlsruhe, Bismarckstr. 10, 76133 Karlsruhe, Germany

Full list of author information is available at the end of the article permits use, sharing, adaptation, distribution and reproduction in any medium or format, as long as you give appropriate credit to the original author(s) and the source, provide a link to the Creative Commons licence, and indicate if changes were made. The images or other third party material in this article are included in the article's Creative Commons licence, unless indicated otherwise in a credit line to the material. If material is not included in the article's Creative Commons licence and your intended use is not permitted by statutory regulation or exceeds the permitted use, you will need to obtain permission directly from the copyright holder. To view a copy of this licence, visit http://creativecommons.org/licenses/by/4.0/. The Creative Commons Public Domain Dedication waiver (http://creativeco mmons.org/publicdomain/zero/1.0/) applies to the data made available in this article, unless otherwise stated in a credit line to the data. 
Keywords: Chronic disease, Health, Cardiorespiratory endurance, Muscular strength, Coordination, Physical activity, Motor performance, Motor abilities, Motor skills, Adolescents

\section{Introduction}

In childhood and adolescence, physical fitness is an essential marker of health [1-3]. High physical fitness performance in childhood and adolescence is associated with reduced present and future risks of disease and premature death $[4,5]$. Most likely, for reasons of limited resources, physical fitness levels are rarely analysed (comprehensively) in health monitoring [6]. To assess the physical fitness levels of younger populations, an appropriate concept must be selected. In this study, a dimension-oriented concept covering a broad age range was selected that consisted of the main dimensions of cardiorespiratory endurance, muscular strength, speed, coordination and flexibility $[2,3]$.

This paper seeks to examine the physical fitness levels of children, adolescents and young adults with chronic asthma. Asthma is the most common pulmonary disease in children and adolescents and is characterised by recurrent attacks of breathlessness, wheezing and other symptoms [7]. During asthma attacks, the lining of the bronchial tubes swells. This causes less airflow into and out of the lungs [7]. The prevalence of asthma has been globally increasing for decades [7-9], with currently more than 339 million affected individuals [7]. In Germany, the 12 -month prevalence of physician-diagnosed asthma in younger populations is stagnant at approximately $4.0 \%$ (3.1\% in girls versus $5.0 \%$ in boys) [10], whereas the lifetime prevalence is documented to be higher at approximately $6.3 \%$ (5.2\% in girls and $7.4 \%$ in boys) [11].

The cause of asthma is thought to be complex. In addition to genetic predispositions, mobility and (changing) environmental exposures that provoke allergic reactions or irritate the airways play a role [7]. The major objective of treatment, therefore, is disease control and reduction of the burden of disease [7, 12]. Asthma is associated with high costs for healthcare systems and society due to school and work absenteeism and therapies [12]. In addition to the burden on society, the disease has a substantial burden on individuals and their families [12]. Sleeplessness during the night and daytime fatigue are typical negative implications [7].

During asthma attacks, physical capacity is reduced in individuals with otherwise normal lung function [9]; apart from this, there are no restrictions on training [13]. Despite the positive effects of regular physical training (less hospitalisation and less medication necessary [13]), individuals with asthma seem to train less frequently and intensively [14]. Family influence or medical advice are discussed as barriers [15]. There are potential explanations for the association of chronic asthma with reduced physical fitness.

A higher state of physical fitness may increase the threshold for developing respiratory symptoms [16], reduce the burden of disease for individuals with asthma and increase their quality of life [15]. Rasmussen et al. [17] found better cardiorespiratory fitness to be associated with better airway reactivity and a reduced risk of developing asthma.

While improvements in cardiopulmonary fitness through physical training are found frequently in individuals with asthma [15], other dimensions of physical fitness, such as muscular strength and coordination, are rarely studied.

Regular physical activity has been found to be a preventative factor for new disease onset of asthma in some studies [18-20]. There is consensus that physical training (as a specific form of physical activity) has proven to be well tolerated in individuals with asthma [13, 15], especially with a medical evaluation before training, adequate monitoring and education [12, 17]. Education comprises, for example, breathing techniques and respiratory exercises.

Studies that directly compare the physical fitness and physical activity levels in children and adolescents with asthma and their non-asthmatic peers have produced inconsistent results. Concerning physical fitness, some studies found children and adolescents with asthma to be less fit than their non-asthmatic peers [21], whereas others reported no difference [22]. With respect to physical activity, some studies reported children and adolescents with asthma to be less active [21,23], whereas others reported no difference in physical activity [22]. Reduced cardiorespiratory fitness was found by Andrade and colleagues [21] in children with moderate and severe asthma in Brazil using the 6-min walk test. This result was described to be directly influenced by the lack of physical activity of the individuals with asthma. Berntsen et al. [22] came to the opposite findings in Norway and did not find reduced cardiorespiratory fitness or reduced physical activity levels in individuals with asthma in contrast to those without asthma.

To identify potential health gaps, this population-based study focuses on the comparison of the physical fitness of children, adolescents and young adults with asthma and their peers without asthma. In addition to cardiorespiratory endurance, this article focuses on two other 
components of physical fitness: muscular strength and coordination. To the best of our knowledge, this is the first study to comprehensively compare the physical fitness levels of individuals with and without asthma in the context of relevant influencing factors.

\section{Methods}

\section{Study population and study design}

These cross-sectional analyses are part of the Motorik Modul Study (MoMo), a long-term population-based study on physical fitness and physical activity in Germany that started in 2003 with a baseline measurement and has a cross-sectional and longitudinal approach [24, 25]. The present study focuses on cross-sectional data collected between 2009-2012 (MoMo wave 1) and between 2014-2017 (MoMo wave 2). MoMo is an in-depth study of the long-term KiGGS study (German Health Interview and Examination Survey for Children and Adolescents) conducted by the Robert Koch Institute [26]. The participants of KiGGS were randomly selected from local population registries in 167 sample points throughout Germany using a stratified multistage probability sampling strategy [26]. These sample points were selected according to the structure of federal states and municipalities of the Federal Republic of Germany. Participants in the MoMo study were randomly recruited from the KiGGS sample, which allows the inclusion of data from the KiGGS study in this analysis [27]. Participants were contacted individually and invited to examination rooms near their homes. In these examination rooms, their physical fitness levels and anthropometric measures were tested, and the participants completed questionnaires. For asthma diagnosis, medical data from the KiGGS study were added and analysed.

\section{Variables}

\section{Socio-economic status}

Socioeconomic status (SES) includes the education, professional status and household income of the participant parents. The different domains were scored on a scale $1-7$ and then combined for a score from 3 to 21 [28]. For each wave the sample was then categorised in three groups while using quintiles $(l o w=$ first quintile | intermediate $=$ second to fourth quintile $\mid$ high $=$ fifth quintile).

\section{Anthropometric measure}

Body height was measured with a portable stadiometer (Seca 213, Hamburg, Germany), and body mass was measured with a digital scale (Seca 813, Hamburg, Germany), both without shoes and with light clothing. Based on this, the BMI $\left(\mathrm{kg} / \mathrm{m}^{2}\right)$ was calculated. Weight status was defined according to Kromeyer-Hauschild et al. [29].

\section{General health status}

From the age of 11 years onwards, the general health status was assessed by a one-item scale: "How would you describe your health in general?" The five responses ranged from "very good", "good", "fair", "poor", to "very poor" [30]. These responses were dichotomised into two categories: "very good/good" and "fair/poor/very poor". General health status was included in the analysis because of its predictive power for morbidity, mortality and use of health services in adults [31].

\section{2-month prevalence of asthma}

Disease-specific data were collected within the KiGGS study by interviews. The questions to determine the 12-month prevalence of asthma were whether a physician had diagnosed asthma and whether it had occurred in the last 12 months. Additionally, information was requested on the use of asthma medication within the last 12 months. The diagnosis of asthma was assumed when physician-diagnosed asthma occurred or when the use of asthma medication was reported within the last 12 months [32].

\section{Physical fitness (PF)}

Physical fitness was measured by means of the MoMo test profile [24], which is based on the systematisation by Bös [2, 3]. All tests of the profile originate from validated test batteries and were pretested and documented in a published test manual [33]. Within this paper, six test items that covered the three dimensions "cardiorespiratory endurance", "muscular strength" and "coordination" were chosen; they statistically had the ability to be modelled and calculated as percentiles. "Cardiorespiratory endurance" was measured by an ergometric test assessing the physical working capacity 170 (PWC170, watts at 170 beats/minute by means of the protocol of the World Health Organization [33]. Muscular strength was measured by the standing long jump, push-up and sit-up tasks. "Coordination" was determined by the jumping sideways test (under time pressure) and by the balancing backwards test (under precision pressure). For each task, we calculated age- and gender-specific percentile curves with our own population-based sample using the LMS transformation method according to Cole and Green [34]. A percentile of 1 represents the lowest age- and gender-specific test performance, whereas a percentile of 99 represents the best age- and gender-specific performance [34]. Within this paper, we combine the percentile values within the same dimension and calculate mean values. In this way, a direct comparison between age- and gender-related heterogeneous groups is possible. In the literature, different cut-offs (at or below the 5th, 9th or 25th 
percentile) have been documented to identify the "at-risk group" $[35,36]$ with potential daily motor problems or potentially pathological diseases. Physical performance at or below the 15th percentile has been documented for gross motor coordination problems [35]. In this study, the cut-off point was used for all three dimensions of physical fitness and served to compare the odds of being physically unfit in individuals with asthma and their peers without asthma.

\section{Physical activity (PA)}

To assess self-reported habitual physical activity, the participants completed the MoMo Physical Activity Questionnaire (MoMo-PAQ), which covers different settings and structures of physical activity, such as sports clubs, leisure time, school, daily activities and overall physical activity [37]. Membership in a sports club, which is an essential setting for physical activity in Germany, was also assessed. The questionnaire is reliable (test-retest reliability: ICC $=0.68$ ) [37]. It consists of 28 questions and covers the settings of physical activity in a normal week, without a defined reference period. Because of the broad age range of the study samples of this analysis, the overall physical activity was chosen as adequate outcome parameter referring to the recommendations of the World Health Organization [38]. Overall physical activity was operationalised for days with at least $60 \mathrm{~min}$ of physical activity and as a percentage with $60 \mathrm{~min}$ of physical activity every day as described by Prochaska, Sallis and Long.

\section{Media consumption}

Media consumption was determined by interview within the KiGGS core survey by asking about daily amounts of time spent watching TV or films, using a computer and playing console games [39]. For participants up to the age of 10 , the parents were asked to estimate the daily amounts, and participants from the age of 11 years and older reported the amounts themselves. The media times were summed and reported in categories. The categories low, intermediate and high media consumption were based on tertiles in relation to the total population of the KiGGS study in the same measurement wave.

\section{Statistical analysis}

The statistical analyses were conducted using IBM SPSS 24 (Chicago, USA). To characterise the study populations with and without asthma, percentages or means and standard deviations (SD) are reported. For the group comparisons, Mann-Whitney U tests and $\mathrm{chi}^{2}$ tests were applied to analyse group differences. The unequal sample sizes of the groups did not influence the test results of the Mann-Whitney U test [40]. The required assumption for the $\mathrm{chi}^{2}$ of expected frequencies greater than five was met. To describe the effect sizes, the Hodge Lehmann estimator for the median differences and Cramer's $\mathrm{V}$ are reported [40]. Cramer's V values greater than 0.1 and lower than 0.3 indicate a small effect, values between 0.3 and 0.5 indicate a medium effect, and values greater than 0.5 indicate a large effect [41]. If the $95 \%$ confidence interval for the median difference contains zero, an effect cannot be assumed. The group characteristics and PA-related behaviours were stratified by gender. This stratification was not necessary for the outcome variable of physical fitness due to the age- and gender-specific format as percentiles. To evaluate the prevalence of PArelated behaviours and physical fitness, odds ratios were calculated for asthma as the risk factor, and 95\% confidence intervals for the odds ratios were reported. Odds ratios are calculated in general to obtain if an assumed risk factor is associated with an outcome variable e.g. a medical condition. In this analysis, the purpose was to identify if asthma is a risk factor for lower physical fitness. If the $95 \%$ CI was greater than one, the prevalence was assumed to be associated with the occurrence of asthma.

\section{Results}

In total 7731 individuals aged 6-30 years were included in this cross-sectional analysis at two measurement waves including 353 individuals with asthma and 7378 without asthma. In wave 1 (2009-2012) $\mathrm{N}=3471$ individuals aged 6-24 years participated in the study: 163 individuals with asthma (4.7\%) and 3308 without asthma (95.3\%). Accordingly, a total of 4260 individuals aged 6-30 years participated in wave 2 (2014-2017): 190 individuals with (4.5\%) and 4070 without asthma (95.5\%). In the groups with asthma, 79\% (wave 1) and 95\% (wave 2) got asthmaspecific medication. A description of the characteristics of the study populations is given in Table 1 .

With respect to age, socioeconomic status, BMI and weight status, the groups did not differ in each wave. Significant differences between the groups were found for gender, with more male individuals in the group with asthma in wave $1\left(\mathrm{chi}^{2}=5.573 ; p=0.018\right.$, Cramer's $V=0.040$ ), and for the general state of health, with poorer general health status in the group with asthma $\left(\mathrm{chi}^{2}=4.063 ; p=0.044\right.$, Cramer's V=0.043). Stratified by gender, a difference in the general state of health was found only in males $\left(\mathrm{chi}^{2}=4.056 ; p=0.044\right.$, Cramer's $\mathrm{V}=0.060)$ but not in females $\left(\mathrm{chi}^{2}=0.771 ; p=0.380\right.$, Cramer's $\mathrm{V}=0.026$ ). After stratification by gender, no other gender-specific differences were detected in wave 1. In wave 2 the difference for the general health status was also significant $\left(\mathrm{chi}^{2}=17.702 ; p<0.001\right.$, Cramer's 
Table 1 Characteristics of the study populations

\begin{tabular}{|c|c|c|c|c|}
\hline \multirow[t]{2}{*}{ Variables } & \multicolumn{2}{|l|}{ Wave 1 (2009-2012) } & \multicolumn{2}{|l|}{ Wave 2 (2014-2017) } \\
\hline & $\begin{array}{l}\text { Individuals with asthma } \\
(\mathrm{n}=163)\end{array}$ & $\begin{array}{l}\text { Reference population } \\
(\mathrm{n}=3308)\end{array}$ & $\begin{array}{l}\text { Individuals with asthma } \\
(\mathrm{n}=190)\end{array}$ & $\begin{array}{l}\text { Reference } \\
\text { population } \\
(n=4070)\end{array}$ \\
\hline Male (\%) | female (\%) & $59 \mid 41$ & $49 \mid 51$ & $53 \mid 47$ & $49 \mid 51$ \\
\hline Age (mean $\pm S D)$ & $13.6 \pm 4.7$ & $13.3 \pm 4.4$ & $14.5 \pm 4.9$ & $14.4 \pm 4.8$ \\
\hline \multicolumn{5}{|l|}{ Socioeconomic status (SES*) } \\
\hline Low (\%) & 7.2 & 8.3 & 7.5 & 8.5 \\
\hline Intermediate (\%) & 65.6 & 65.3 & 68.1 & 64.4 \\
\hline High (\%) & 27.2 & 26.4 & 24.4 & 27.1 \\
\hline $\mathrm{BMI}\left(\mathrm{kg} / \mathrm{m}^{2}\right)($ mean $\pm \mathrm{SD})$ & $19.9 \pm 4.2$ & $19.7 \pm 4.2$ & $20.9 \pm 4.8$ & $20.2 \pm 4.2$ \\
\hline \multicolumn{5}{|l|}{ Weight status** } \\
\hline Underweight (\%) & 5.5 & 6.9 & 4.9 & 7.4 \\
\hline Normal weight (\%) & 80.4 & 78.8 & 76.1 & 76.7 \\
\hline Overweight (\%) & 7.4 & 8.2 & 9.8 & 10.0 \\
\hline Obese (\%) & 6.7 & 6.0 & 9.2 & 5.9 \\
\hline \multicolumn{5}{|l|}{ General health status*** } \\
\hline Very good/good (\%) & 84.8 & 90.6 & 80.6 & 91.2 \\
\hline Fair/poor/very poor (\%) & 15.2 & 9.4 & 19.4 & 8.8 \\
\hline
\end{tabular}

Data are either percent (\%) or mean values (mean) \pm standard deviation (SD); SES* based on Lampert et al. [28]; weight status** based on Kromeyer-Hauschild et al. [29]; general health status*** based on De Bruin et al. [30]

$\mathrm{V}=0.076$ ) whereas the gender was not to be found different for the group with or without asthma.

Individuals with and without asthma showed similar overall physical activity as measured by at least $60 \mathrm{~min}$ of moderate to vigorous physical activity and by the percentage of sufficiently active individuals at both measurement waves. Membership in sports clubs and media consumption also did not differ statistically between the individuals with and without asthma at both measurement waves (Table 2). Stratified by gender, the results were similar.
At Wave 1 (2009-2012), individuals with and without asthma had comparable cardiovascular fitness, muscular strength and coordination (Table 3). The Mann-Whitney $\mathrm{U}$ test showed nonrelevant $p$ values for all three components of physical fitness, and the Hodge-Lehmann measure of effect size included zero (meaning that no relevant effect was detected). At Wave 2 (2014-2017), individuals with asthma again had comparable cardiovascular fitness and muscular strength, but a slightly lower coordination performance in comparison to the reference population $(p=0.041 ; \mathrm{HL}=4.125$, CI of HL 0.155-8.125).

Table 2 Prevalence of PA-related behaviours in individuals with asthma and their non-asthmatic peers

\begin{tabular}{|c|c|c|c|c|}
\hline \multirow[t]{2}{*}{ Variables } & \multicolumn{2}{|l|}{ Wave 1 (2009-2012) } & \multicolumn{2}{|l|}{ Wave 2 (2014-2017) } \\
\hline & Individuals with asthma & Reference population & Individuals with asthma & $\begin{array}{l}\text { Reference } \\
\text { population }\end{array}$ \\
\hline Days with at least $60 \mathrm{~min} P A^{*}($ mean $\pm S D)$ & $3.8 \pm 1.8$ & $3.8 \pm 1.7$ & $3.7 \pm 1.8$ & $3.8 \pm 1.7$ \\
\hline Sufficiently active** $(\%)$ & 16.8 & 13.3 & 10.9 & 12.6 \\
\hline Membership sports club (\%) & 70.4 & 63.9 & 60.1 & 62.6 \\
\hline Low media consumption*** (\%) & 32.7 & 36.7 & 45.1 & 50.5 \\
\hline Intermediate media consumption (\%) & 34.0 & 32.0 & 32.4 & 27.1 \\
\hline High media consumption (\%) & 33.3 & 31.3 & 22.5 & 22.4 \\
\hline
\end{tabular}

Data are mean values (mean) \pm standard deviation (SD) or percent (\%)

*Days per week with at least 60 min of moderate to vigorous physical activity, ${ }^{* *}$ percentage sufficiently active (60 min every day) based on Prochaska et al. [50], media consumption ${ }^{* * *}$ based on tertiles in relation to the total population of the KiGGS study in wave 1 and on tertiles in relation to the total population of the MoMo study in wave 2 
The prevalence of PA-related exposure was not associated with the occurrence of asthma. The odds ratios for being less physically active were not elevated for individuals with asthma (Table 4). Children, adolescents and young adults with asthma did not have an elevated risk of being physically unfit ( $\leq 15$ th age- and gender-specific percentile) for their cardiorespiratory endurance and muscular strength (Table 5). The odds of being at risk for coordination problems was not elevated at wave 1 , but doubled for the group with asthma at wave 2 (OR 2.013, 95\% CI 1.334-3.036).

\section{Discussion}

The distribution of individuals with asthma at both measurement waves corresponded to the age- and sex-specific general population in Germany, which is attributable to the representative nature of the study. Higher prevalence rates of asthma in males, especially between the ages of 10 and 15 years, have also been found in other population-based studies in Germany [10]. In consideration of the described burden of disease [10], it is not surprising that the group with the diagnosis of asthma reported a poorer general state of health. This "health gap" can be an indicator of worse lung function parameters or participation disturbances. Due to the large-scale character of this large scale study, there were no embedded lung function diagnostics.

Children, adolescents and young adults with asthma in Germany did not have reduced physical fitness levels in the dimensions of cardiorespiratory endurance and muscular strength. Within the dimension coordination, the results were ambiguous depending on the measurement wave (wave 1: no difference, wave 2: small difference).

The finding of similar levels of cardiorespiratory endurance performance in individuals with and without asthma is supported by the findings of Berntsen et al. [22], who measured $n=95$ individuals with asthma versus $n=79$ without asthma by a treadmill test. This finding is also

Table 3 Physical fitness in individuals with asthma in comparison to their non-asthmatic peers

\begin{tabular}{|c|c|c|c|c|}
\hline \multirow[t]{2}{*}{ Variables } & \multicolumn{2}{|l|}{ Wave 1 (2009-2012) } & \multicolumn{2}{|l|}{ Wave 2 (2014-2017) } \\
\hline & Individuals with asthma & Reference population & Individuals with asthma & Reference population \\
\hline Cardiorespiratory endurance* & $48.9 \pm 28.4$ & $51.4 \pm 28.9$ & $50.0 \pm 28.7$ & $53.4 \pm 28.0$ \\
\hline Mann-Whitney U test & \multicolumn{2}{|c|}{$p=0.390 ; \mathrm{HL}=2.497(\mathrm{Cl}-3.128-8.263)$} & \multicolumn{2}{|c|}{$p=0.155 ; \mathrm{HL}=3.451(\mathrm{Cl}-1.243-8.349)$} \\
\hline Muscular strength & $55.3 \pm 24.3$ & $52.6 \pm 23.0$ & $47.3 \pm 24.9$ & $50.5 \pm 23.3$ \\
\hline Mann-Whitney U test & \multicolumn{2}{|c|}{$p=0.139 ; \mathrm{HL}=-3.051(\mathrm{Cl}-7.178-0.997)$} & \multicolumn{2}{|c|}{$p=0.060 ; \mathrm{HL}=3.638(\mathrm{Cl}-0.152-7.434)$} \\
\hline Coordination & $52.5 \pm 25.5$ & $53.4 \pm 24.2$ & $47.6 \pm 26.7$ & $51.7 \pm 24.3$ \\
\hline Mann-Whitney U test & \multicolumn{2}{|c|}{$p=0.719 ; \mathrm{HL}=0.754(\mathrm{Cl}-3.377-4.887)$} & \multicolumn{2}{|c|}{$p=0.041 ; \mathrm{HL}=4.125(\mathrm{Cl} 0.155-8.125)$} \\
\hline
\end{tabular}

*Data are mean percentiles based on Niessner et al. [34] \pm standard deviations (SD), $p$ values and effect size Hodge Lehmann (HL) with related $95 \%$ confidence intervals $(\mathrm{Cl})$

Table 4 Odds ratios (OR) for PA-related behaviours

\begin{tabular}{|c|c|c|}
\hline \multirow[t]{2}{*}{ Prevalence of PA-related behaviours } & Wave 1 (2009-2012) & Wave 2 (2014-2017) \\
\hline & Asthma versus reference population & Asthma versus reference population \\
\hline Sufficiently active versus not sufficiently active & OR 0.765 (95\% Cl 0.500-1.170) & OR 1.179 (95\% Cl 0.734-1.893) \\
\hline Membership sports club versusnon-membership & OR 0.742 (95\% Cl 0.500-1.170) & OR 1.113 (95\% Cl 0.822-1.507) \\
\hline High versus intermediate or low media consumption & OR 1.099 (95\% Cl 0.524-1.051) & OR 1.006 (95\% Cl 0.705-1.436) \\
\hline
\end{tabular}

Data are odds ratios (ORs) and 95\% confidence intervals (Cls)

Table 5 Odds ratios (OR) for being physically unfit ( $\leq 15$ th age- and gender-specific percentile)

\begin{tabular}{|c|c|c|}
\hline \multirow[t]{2}{*}{ Prevalence physical fitness } & Wave 1 (2009-2012) & Wave 2 (2014-2017) \\
\hline & Asthma versus reference population & Asthma versus reference population \\
\hline $\begin{array}{l}\leq 15 \text { th percentile cardiorespiratory } \\
\text { Endurance }\end{array}$ & OR 1.069 (95\% Cl 0.621-1.838) & OR 1.393 (95\% Cl 0.876-2.215) \\
\hline$\leq 15$ th percentile muscular strength & OR 1.214 (95\% Cl 0.628-2.346) & OR 1.337 (95\% Cl 0.811-2.205) \\
\hline$\leq 15$ th percentile coordination & OR 0.891 (95\% Cl 0.463-1.714) & OR $2.013(95 \%$ Cl 1.334-3.036) \\
\hline
\end{tabular}

Percentiles based on Niessner et al. [34], data are odds ratios (ORs) and 95\% confidence intervals (Cls) 
supported by Santuz et al. [42], who compared $n=80$ individuals with asthma with $\mathrm{n}=80$ non-asthmatic peers using a treadmill test. In contrast, de Andrade et al. [21] found lower levels of cardiorespiratory endurance in $\mathrm{n}=40$ individuals with asthma (measured as a shorter walking distance within the 6-min walking test) in comparison to predicted values for healthy individuals. The findings concerning muscular strength and coordination performance could not be compared to other studies. As muscular strength [43] and coordination performance (1) are linked to health, this gap in the knowledge should be filled to determine whether health opportunities are (un) equally distributed. It must be noticed that the results in relation to coordination performance were not consistent in the wave 1 and wave 2 measurement of this study while all other outcomes were stable. However, when calculating a more complex model with a multinomial logistic regression with the confounders sex, age, BMI, general health status, physical activity, physical fitness, media consumption and SES this differences can no longer be detected (wave1: Nagelkerkes- $\mathrm{R}^{2}=0.085, p=0.292$; wave2: Nagelkerkes- $\mathrm{R}^{2}=0.032, p=0.092$ ). Therefore, we assume that the differences in coordination performance in wave 2 in the odds ratios either occur due to random effects or due to differences in setting-specific physical activity which we did not cover precisely in the analysis of the influencing factors. Due to the broad age range, we had to choose appropriate physical activity variables with information across all age groups. In this study, overall physical activity, overall organised physical activity and media consumption did not differ between the individuals with and without asthma even though disease-specific obstacles in engaging in physical activity might exist.

Similar levels of overall physical activity in individuals with asthma have also been found in other studies $[22,44,45]$. In a study from the year $2018, \mathrm{n}=65$ young adults with asthma reported lower physical activity levels in concerning vigorous physical activity in comparison to controls without asthma. Negative expectations and fearavoidance beliefs were discussed as relevant predictors of PA levels in young adults with asthma [46]. For future studies analysing the physical fitness levels of children, adolescents and adults with asthma, the influencing factor physical activity should be analysed more differentiated and the amount and proportion of vigorous physical activity should be included into the analysis.

In all groups of this study, only a small percentage met the 60-min threshold of moderate to vigorous physical activity every day (wave 1: $16.8 \%$ asthma, $13.3 \%$ nonasthmatic reference group; wave 2: $10.9 \%$ asthma, $12.6 \%$ non-asthmatic reference group). This finding is in line with many other studies; Tremblay et al. [47] refer to it as a "physical inactivity crisis". Insufficient movement neglects to compensate for the health gap, especially in individuals with chronic diseases.

A possible explanation for the non-existent differences in physical fitness levels in most dimensions between individuals with and without asthma is adequate pharmacotherapy (a large proportion of the individuals with asthma receive asthma-specific medication) and education, which might have had a compensating effect. Education was not assessed in this population-based study, therefore this hypothesis cannot be proved. But it is known from the literature that one-third of all children and adolescents with asthma in Germany received special education between 2010 and 2017. They joined the structured and evaluated patient education programme offered by a patient education network all over Germany [48]. The main topics of the programme are knowledge about asthma, symptoms, self-awareness, avoidance of asthma triggers, breath control, inhalation techniques, management of acute dyspnoea and knowledge about physical training [49]. The continuation of qualityassured education programmes seems promising and offers new tailored education programmes for teachers and trainers. Doctors, clinicians, public health actors, teachers and trainers should cooperate (more) closely to support children, adolescents and young adults with asthma to become and remain physically active and fit.

There are several limitations of the study that must be considered. The two groups were formed by the variable of having or not having physician-diagnosed asthma, assessed by interview. This is a weak diagnostic assessment, but due to the population-based character and limited resources, it is an unavoidable limitation. Presumably, individuals with severe forms of asthma and poor disease control did not participate equally in the KiGGS-/MoMo study in comparison to those with mild forms and healthy individuals. At the same time, in the group without asthma, there is likely a proportion of individuals with undiagnosed asthma. For future smaller comparisons, a parameter of lung function should be included. The cut-off point at or below the 15th percentile needs to be questioned in future studies to find the most accurate threshold. We chose this cut-off because of the position between the 5th and 25th percentiles, as elaborated in former studies. The assessment of physical activity realised by questionnaire could be associated with a lack of precision. The major strengths of the present analysis are the large sample sizes, the population-based character of the study and the objective and comprehensive comparisons of physical fitness, including the components of cardiorespiratory endurance, coordination and muscular strength. Furthermore, the analogue measurement of outcome parameters and influencing factors in both groups is worth to be mentioned. 


\section{Conclusions}

The present population-based study provides a comparison of the physical fitness levels of individuals with and without asthma, focusing on cardiorespiratory endurance, muscular strength and coordination performance as well as physical activity levels. To the best of our knowledge, no other studies have compared individuals with and without asthma within these three health-related dimensions of physical fitness in the context of relevant influencing factors. The results of the comparisons at the two measurement waves of the population-based study were remarkably stable except for the coordination performance. In this study, individuals with asthma were as physically fit in relation to cardiorespiratory endurance and muscular strength and they were as physically active as their peers without asthma. Future studies should deepen the evidence in relation to coordination performance and should explore how pharmacotherapy and education influence physical capacity and physical fitness. It can be perceived negatively that only $16.8 \%$ (wave 1 ) and $10.9 \%$ (wave 2 ) of the individuals with asthma met the 60-min threshold of moderate to vigorous physical activity every day. This indicates lost potential to positively influence health and health-related quality of life in order to overcome the health gap.

\begin{abstract}
Abbreviations
KiGGS: German health interview and examination survey for children and adolescents; MoMo: Motorik Modul; HL: Hodge Lehmann (effect size); SD: Standard deviation; SES: Socioeconomic status; BMI: Body mass index $\left(\mathrm{kg} / \mathrm{m}^{2}\right)$; PWC 170: Physical working capacity 170; MoMo-PAQ: MoMo physical activity questionnaire; $\mathrm{Cl}$ : Confidence interval; PA: Physical activity; OR: Odds ratios.
\end{abstract}

\section{Acknowledgements}

Thank you to the MoMo participants for their cooperation. Special thanks to the test leaders and the entire MoMo team.

\section{Authors' contributions}

AHD wrote the manuscript draft. DO, AHD and CN performed the statistical analyses. RJ assisted in data interpretation. AW, CN, DO and RJ provided critical input for the manuscript. All authors read, revised and approved the final version of the manuscript.

\section{Funding}

Open Access funding enabled and organized by Projekt DEAL. This work was supported by the Federal Ministry of Education and Research [01ER1503] within the research program "long-term studies" in public health research. It was developed within the Motorik-Modul Longitudinal Study (MoMo) (2009-2021): Physical fitness and physical activity as determinants of health development in children and adolescents. The funding source played no role in the study design, data collection, analysis and interpretation but agreed to the submission of this manuscript.

\section{Availability of data and materials}

The datasets generated and/or analysed during the current study are not publicly available because the Federal Office for the Protection of Data explicitly forbid making the data publicly available because informed consent from the study participants did not cover the public deposition of data. The datasets are available from the corresponding author on reasonable request.

\section{Declarations}

Ethical approval and consent to participate

The study was approved by the ethics committees of Konstanz University (2008) and by the Karlsruhe Institute of Technology (2014), and conducted in agreement with the Declaration of Helsinki. Participation in the study was voluntary. In advance of their participation, all of the participants, their parents /custodians were fully informed about the aims and contents of the study as well as about data protection. Written informed consent was obtained from each participant (parents/ custodians). The participants were informed that all data collected would be processed anonymously.

\section{Consent for publication \\ Not applicable.}

\section{Competing interests}

The authors declare that they have no competing interests.

\section{Author details}

${ }^{1}$ University of Education Karlsruhe, Bismarckstr. 10, 76133 Karlsruhe, Germany. ${ }^{2}$ Rehabilitation Centre for Children With Respiratory Diseases, Fachkliniken Wangen, Am Vogelherd 14, 88239 Wangen, Germany. ${ }^{3}$ Karlsruhe Institute of Technology, Engler-Bunte-Ring 15, 76131 Karlsruhe, Germany.

Received: 24 December 2020 Accepted: 12 October 2021

Published online: 22 October 2021

\section{References}

1. Ortega FB, Ruiz JR, Castillo MJ, Sjöström M. Physical fitness in childhood and adolescence: a powerful marker of health. Int J Obes. 2008;32:1-11.

2. Hanssen-Doose A, Kunina-Habenicht O, Oriwol D, Niessner C, Woll A, Worth A. Predictive value of physical fitness on self-rated health: a longitudinal study. Scand J Med Sci Sports. 2020. https://doi.org/10.1111/sms. 13841.

3. Bös K, Worth A, Opper E, Oberger J, Romahn N, Wagner M, Jekauc D, Mess F, Woll A. Motorik-Modul: eine Studie zur motorischen Leistungsfähigkeit und körperlich-sportlichen Aktivität von Kindern und Jugendlichen in Deutschland; Abschlussbericht zum Forschungsprojekt. Baden-Baden: Nomos; 2009. ISBN: 9783832944988: 1-420. https://www.bmfsfi.de/blob/ 94390/dc4ceb29b7415827c48a6a313b224602/motorik-modul-data.pdf. Accessed 16 Dec 2020.

4. Högström G, Nordström A, Nordström P. Aerobic fitness in late adolescence and the risk of early death: a prospective cohort study of 1.3 million Swedish men. Int J Epidemiol. 2016;45(5):1159-68.

5. Sato M, Kodama S, Sugawara A, Saito K, Sone H. Physical fitness during adolescence and adult mortality. Epidemiology. 2009;20(3):463-4

6. Tremblay MS, Shields M, Laviolette M, Craig CL, Janssen I, Gorber SC Fitness of Canadian children and youth: results from the 2007-2009 Canadian Health Measures Survey. Health Rep. 2010;21(1):7.

7. World Health Organisation WHO. Fact sheet on asthma 2020. http://www. who.int/en/news-room/fact-sheets/detail/asthma. Accessed $13 \mathrm{Dec}$ 2020.

8. Vos T, Abajobir AA, Abate KH, Abbafati C, Abbas KM, Abd-Allah F, Abdulkader RS, Abdulle AM, Abebo TA, Abera SF, Aboyans V. Global, regional, and national incidence, prevalence, and years lived with disability for 328 diseases and injuries for 195 countries, 1990-2016: a systematic analysis for the Global Burden of Disease Study 2016. Lancet. 2017;390(10100):1211-59.

9. Pearce N, Aït-Khaled N, Beasley R, Mallol J, Keil U, Mitchell E, Robertson C. Worldwide trends in the prevalence of asthma symptoms: phase III of the International Study of Asthma and Allergies in Childhood (ISAAC). Thorax. 2007;62:758-66.

10. Poethko-Müller C, Thamm M, Thamm R. Allergic rhinitis and asthma among children and adolescents in Germany. Results of the cross-sectional KiGGS Wave 2 study and trends. J Health Monit. 2018:3:52-6.

11. Schmitz R, Thamm M, Ellert U, Kalcklösch M, Schlaud $M$, KiGGS Study Group. Verbreitung häufiger Allergien bei Kindern und Jugendlichen in Deutschland. 
Bundesgesundheitsblatt-Gesundheitsforschung-Gesundheitsschutz. 2014;57:771-8.

12. Papadopoulos NG, Arakawa H, Carlsen KH, Custovic A, Gern J, Lemanske $\mathrm{R}, \mathrm{Zar} \mathrm{H}$. International consensus on (ICON) pediatric asthma. Allergy. 2012;67:976-97.

13. Kriemler S, Schmitt H. Bewegung und Sport bei ausgewählten chronischen Erkrankungen. In: Breuer C, Joisten, Schmidt W, editors. Vierter Deutscher Kinder- und Jugendsportbericht. Hofmann: Schorndorf; 2020. p. 147-76.

14. Berntsen S, Carlsen KCL, Anderssen SA, Mowinckel P, Carlsen KH. Factors associated with aerobic fitness in adolescents with asthma. Respir Med. 2013;107:1164-71.

15. Carson KV, Chandratilleke MG, Picot J, Brinn MP, Esterman AJ, Smith BJ. Physical training for asthma. Cochrane Database Syst Rev. 2013;9:1-72.

16. Janssen I. Physical activity, fitness, and cardiac, vascular, and pulmonary morbidities. In: Bouchard C, Blair SN, Haskell W, editors. Physical activity and health. 2nd ed. Champaign: Human Kinetics; 2012. p. 185-95.

17. Rasmussen F, Lambrechtsen J, Siersted HC, Hansen HS, Hansen NC. Low physical fitness in childhood is associated with the development of asthma in young adulthood: the Odense schoolchild study. Eur Respir J. 2000;16:866-70

18. Eijkemans M, Mommers M, Jos MT, Thijs C, Prins MH. Physical activity and asthma: a systematic review and meta-analysis. PLoS ONE. 2012;7:50775.

19. Guldberg-Møller J, Hancox B, Mikkelsen D, Hansen HS, Rasmussen F. Physical fitness and amount of asthma and asthma-like symptoms from childhood to adulthood. Clin Respir J. 2015;9:314-21.

20. Vogelberg C, Hirsch T, Radon K, Dressel H, Windstetter D, Weinmayr G, Leupold W. Leisure time activity and new onset of wheezing during adolescence. Eur Respir J. 2007;30:672-6.

21. de Andrade LB, Silva DA, Salgado TL, Figueroa JN, Lucena-Silva N, Britto MC. Comparison of six-minute walk test in children with moderate/ severe asthma with reference values for healthy children. J Pediatr. 2014;90:250-7.

22. Berntsen S, Carlsen KCL, Anderssen SA, Mowinckel P, Hageberg R, Bueso AK, Carlsen KH. Norwegian adolescents with asthma are physical active and fit. Allergy. 2009;64:421-6.

23. Williams B, Powell A, Hoskins G, Neville R. Exploring and explaining low participation in physical activity among children and young people with asthma: a review. BMC Fam Pract. 2008;9:40.

24. Woll A, Albrecht C, Worth A. Motorik-Module (MoMo) - the KiGGS Wave 2 module to survey motor performance and physical activity. J Health Monit. 2017;2:63-70.

25. Wagner MO, Bös K, Jekauc D, Karger C, Mewes N, Oberger J, Reimers AK, Schlenker L, Worth A, Woll A. Cohort profile: the Motorik-Modul (MoMo) longitudinal study - physical fitness and physical activity as determinants of health development in German children and adolescents. Int J Epidemiol. 2014;43:1410-6.

26. Kurth BM, Kamtsiuris P, Hölling H, Schlaud M, Dölle R, Ellert U, Neuhauser $H$. The challenge of comprehensively mapping children's health in a nation-wide health survey: design of the German KiGGS-Study. BMC Public Health. 2008:8:196.

27. Schmidt SC, Woll A. Longitudinal drop-out and weighting against its bias. BMC Med Res Methodol. 2017:17:164

28. Lampert T, Müters S, Stolzenberg H, Kroll LE, KiGGS Study Group. Messung des sozioökonomischen Status in der KiGGS-Studie. Bundesgesundheitsblatt-Gesundheitsforschung-Gesundheitsschutz. 2014;57:762-70.

29. Kromeyer-Hauschild K, Wabitsch M, Kunze D, Geller F, Geiß HC, Hesse V. Perzentile für den body-mass-index für das Kinder- und Jugendalter unter Heranziehung verschiedener deutscher Stichproben. Monatszeitschrift Kinderheilkd. 2001;149:807-18.

30. De Bruin A, Picavet HS, Nossikov A. Health interview surveys. Towards international harmonization of methods and instruments. WHO Reg Publ Eur Ser. 1996;58:1-161.

31. Breidablik HJ, Meland E, Lydersen S. Self-rated health during adolescence: stability and predictors of change (Young-HUNT study, Norway). Euro J Public Health. 2008;19:73-8.

32. Laußmann D, Haftenberger M, Langen U, Eis D. Einflussfaktoren für Asthma bronchiale bei Kindern und Jugendlichen in Deutschland.
Bundesgesundheitsblatt-Gesundheitsforschung-Gesundheitsschutz. 2012;55:308-17.

33. Worth A, Woll A, Albrecht C, Karger C, Mewes N, Oberger J, Bös K. MoMoLong term study "Physical Fitness and Physical Activity as Determinants of Health Development in Children and Adolescents"Testmanual zu den motorischen Tests und den anthropometrischen Messungen. (Publication in German). Karlsruhe: KIT Scientific Reports, 7700, Karlsruhe Institute of Technology; 2015. https://www.ksp.kit.edu/9783731503958. Accessed 11 Sept 2019 (German language).

34. Niessner C, Utesch T, Oriwol D, Hanssen-Doose A, Schmidt SC, Woll A, Bös K, Worth A. Representative percentile curves of physical fitness from early childhood to early adulthood: the MoMo study. Front Public Health. 2020;8:458

35. Cairney J, Rigoli D, Piek J. Developmental coordination disorder and internalizing problems in children: the environmental stress hypothesis elaborated. Dev Rev. 2013;33:224-38.

36. Ortega FB, Ruiz JR, Castillo MJ, Moreno LA, González-Gross M, Wärnberg J, Gutiérrez Á, Avena Group. Low level of physical fitness in Spanish adolescents. Relevance for future cardiovascular health (AVENA study). Rev Esp Cardiol (English Edition). 2005;58(8):898-909.

37. Jekauc D, Wagner MO, Kahlert D, Woll A. Reliability and validity of MoMophysical-activity-questionnaire for adolescents (MoMo-AFB). Diagnostica. 2013;59:100-11.

38. World Health Organization. Global recommendations on physical activity for health. Geneva: World Health Organization: 2011. http://apps.who.int/ iris/bitstream/10665/44399/1/9789241599979_eng.pdf. Accessed 29 Aug 2021.

39. Lampert T, Sygusch R, Schlack R. Nutzung elektronischer Medien im Jugendalter. Bundesgesundheitsblatt-Gesundheitsforschung-Gesundheitsschutz. 2007;50:643-52. (German language).

40. Stonehouse JM, Forrester GJ. Robustness of the $t$ and $U$ tests under combined assumption violations. J Appl Stat. 1998;25:63-74.

41. Sheskin DJ. Handbook of parametric and nonparametric statistical procedures. 5th ed. Boca Raton: CRC; 2011.

42. Santuz P, Baraldi E, Filippone M, Zacchello F. Exercise performance in children with asthma: is it different from that of healthy controls? Eur Respir J. 1997;10:1254-60

43. Wolfe RR. The underappreciated role of muscle in health and disease. Am J Clin Nutr. 2006;84:475-82.

44. Gannotti M, Veneri D, Roberts D. Weight status and physical activity in third graders with chronic health conditions. Pediatr Phys Ther. 2007;19:301-8.

45. van Gent $R$, van der Ent CK, van Essen-Zandvliet LE, Rovers MM, Kimpen $J \mathrm{~L}$, de Meer G, Klijn PH. No differences in physical activity in (un) diagnosed asthma and healthy controls. Pediatr Pulmonol. 2007;42:1018-23.

46. Janssens T, Dupont L, VonLeupoldt A. Exercise fear-avoidance beliefs and self-reported physical activity in young adults with asthma and healthy controls. Eur Respir J. 2018;52(Suppl 62):PA2479.

47. Tremblay MS, Gray CE, Akinroye K, Harrington DM, Katzmarzyk PT, Lambert EV, Prista A. Physical activity of children: a global matrix of grades comparing 15 countries. J Phys Act Health. 2014;11:113-25.

48. Schauerte G. Asthmaschulung - aktueller Stand und Ausblick. Zeitschrift der Gesellschaft für Pädiatrische Pneumologie. 2018;21:28-30. (German language).

49. AG Asthmaschulung im Kindes- und Jugendalter. Qualitätsmanagement in der Asthmaschulung von Kindern und Jugendlichen. 4rd ed. Wangen im Allgäu: iKuh-Verlag; 2013. (German language).

50. Prochaska JJ, Sallis J, Long B. A physical activity screening measure for use with adolescents in primary care. Arch Pediatr Adolesc Med. 2001;155(5):554-9. https://doi.org/10.1001/archpedi.155.5.554.

\section{Publisher's Note}

Springer Nature remains neutral with regard to jurisdictional claims in published maps and institutional affiliations. 